\title{
Inovação gerencial em municípios: análise exploratória das prá- ticas de gestão do Plano Estratégico de Juiz de Fora
}

\section{Management innovation in cities: an exploratory analysis of the practices of ma- nagement of the Strategic Plan of Juiz de Fora}

\author{
Virgilio Cézar da Silva e Oliveira ${ }^{1}$ \\ Luis Carlos Ferreira de Sousa Oliveira ${ }^{2}$ \\ Euler David de Siqueira ${ }^{3}$ \\ Mozar José de Brito ${ }^{4}$
}

\section{Resumo}

Este artigo procura discutir as práticas de gestão associadas ao plano estratégico do município mineiro de Juiz de Fora (PlanoJF). Para tanto, recupera algumas características da intervenção estatal entre as décadas de 1930 e 1980 no Brasil. Detalha, ainda, alguns fatos que, a partir dos anos 1990, alteraram a natureza desse processo. A reflexão sobre referências teóricas e as evidências coletadas por meio de entrevistas pessoais, da observação não-participante e da análise documental possibilitam, ao final do artigo, a descrição do plano, a análise dos mecanismos de gestão conduzidos por seu comitê executivo e a exposição de algumas constatações.

Palavras-chave: municípios; gestão pública; planejamento estratégico municipal.

\section{Abstract}

This article aims to discuss practices of management associated to the Strategic Plan of Juiz de Fora City (Plano JF). In this sense, this article remembers us some characteristics of the State intervention between the 1930s and the 1980s in Brazil. It also details some facts that have modified the nature of this process since the 1990s. The reflection on theoretical references and the evidences obtained by personal interviews, non-participant observation and documentary analysis makes possible the description of the Plano JF, the analysis of management mechanisms lead by its executive committee and the exposition of some conclusions.

Keywords: city; public management; municipal strategic plan.

\section{Introdução}

A partir da década de 1990, movimentos correlatos promoveram mudanças significativas no panorama sociopolítico brasileiro. Inicialmente, o poder central passou a transferir recursos e responsabilidades à sociedade civil

\footnotetext{
${ }^{1}$ Doutorando em Administração pelo PPGAD/UFLA. Endereço: Universidade Federal de Lavras - Programa de Pós-Graduação em Administração. Caixa Postal 37, Campus Universitário - Lavras, MG - Brasil - CEP: 37200-000 E-mail: virgilio@ufla.br.

${ }^{2}$ Doutor em Comunicação pela Universidade Autônoma de Barcelona - Espanha. Professor e Pesquisador do PPGAD/UFLA. Endereço: Universidade Federal de Lavras - Programa de Pós-Graduação em Administração. Caixa Postal 37- Campus Universitário - Lavras, MG - Brasil - CEP 37.200.000. E-mail: Icsousa@ufla.br.

${ }^{3}$ Doutor em Sociologia pelo Instituto de Filosofia e Ciências Sociais da UFRJ. Professor e pesquisador do Programa de Pós-Graduação em Ciências Sociais e do Departamento de Turismo da UFJF. Endereço: Universidade Federal de Juiz de Fora - Departamento de Turismo. Campus Universitário - Juiz de Fora, MG - Brasil CEP 36.036.330. E-mail: euler.david@ufjf.edu.br..

${ }^{4}$ Doutor em Administração pela USP. Pesquisador do CNPq e da FAPEMIG. Professor e Coordenador do PPGAD/UFLA. Endereço: Universidade Federal de Lavras Programa de Pós-Graduação em Administração. Caixa Postal 37 - Campus Universitário - Lavras, MG - Brasil - CEP 37.200.000. E-mail: mozarjdb@ufla.br.

Artigo recebido em julho de 2005 e aceito para publicação em junho de 2006.
} 
e aos demais níveis de governo (especialmente para os municípios). Em contrapartida, esses agentes ampliaram sua mobilização diante das demandas coletivas.

O inchaço estatal, fenômeno mundial registrado entre 1930 e 1980, contribuiu para a consolidação no Brasil de um Estado empreendedor. Era função do Estado promover infra-estrutura para empresas e cidadãos, produzir insumos industriais e a prestação monopolista de serviços públicos (BRESSER-PEREIRA, 1997). Esse escopo de atribuições, insustentável nos anos seguintes, motivou a descentralização de atividades e a procura por novos arranjos institucionais capazes de coordenar esforços públicos e privados.

Entre esses modelos está o planejamento estratégico urbano, que busca extrair da sociedade projetos de interesse comum e recursos para implementá-los. Entretanto, sua emergência só se tornou viável quando os municípios puderam planejar seu território, ação prevista na Constituição Federal de 1988 e detalhada pelo Estatuto da Cidade aprovado em 2001.

A consolidação desse instrumento resulta de um trabalho de quatro décadas, iniciado pelos debates do Seminário de Habitação e Reforma Urbana, de 1963. O Movimento pela Reforma Urbana, instituído anos depois, inseriu definitivamente na pauta de reivindicações sociais o direito à cidade e à cidadania, a gestão democrática da cidade e a função social da cidade e da propriedade (GRAZIA, 2001).

A partir dessas considerações, este artigo investiga o Plano Estratégico da Cidade de Juiz de Fora (MG), num esforço para detalhar seu processo de elaboração, suas características e as práticas de gestão capitaneadas por seu órgão executivo. Suas constatações fundamentam-se em entrevistas pessoais, na observação nãoparticipante e numa análise documental.

Confere relevância a esta pesquisa a análise qualitativa de uma iniciativa contemporânea e participativa de planejamento público. Além disso, ao focalizar as rotinas de gestão, o estudo pôde detalhar soluções emergentes, não encontradas na literatura consultada e não incluídas no documento formal do plano. Finalmente, a avaliação dos resultados do Plano Estratégico de Juiz de Fora anos depois de sua elaboração contemplou as externalidades políticas desse instrumento, fato especialmente importante para os gestores que pretendem implementálo.

\section{Planejamento público, planejamento urbano e planejamento estratégico municipal}

O planejamento, definido como o delineamento prévio de uma ação, representa uma atividade amplamente legitimada nos dias atuais. Ele pode servir a múltiplos sujeitos (organização, nação etc.) e objetivos (econômico, militar etc.) apresentando distinta natureza (estratégica, operacional etc.) e vigência (curto prazo, longo prazo etc.). Suas características essenciais são a projeção futura, a busca por objetivos específicos, a orientação para um sujeito, a opção racional entre meios alternativos e o ordenamento lógico de ações (MIGLIOLI, 1982).

Para contextualizar a análise das práticas de gestão do Plano Estratégico de Juiz de Fora, esta seção discutirá de modo sucinto os processos de planejamento público e urbano no Brasil. Seu propósito é ressaltar a transferência de recursos e responsabilidades para os municípios após a mudança do padrão de intervenção estatal, assim como o desenvolvimento de novos (e democráticos) mecanismos de gestão urbana. A apresentação do plano estratégico municipal visa detalhar suas especificidades, diferenciando-o do planejamento estratégico corporativo.

\section{Planejamento público no Brasil}

Em países capitalistas, o planejamento surge como uma técnica capaz de favorecer o alcance de metas econômicas. Seu emprego como instrumento público foi motivado pela depressão de 1929 (agravada pelo caráter liberal dos governos), pela urgência de se recuperar nações beligerantes e pela necessidade de programação do desenvolvimento em países periféricos, onde a planificação "[...] tinha o mérito de alcançar por esforço deliberado e racional, resultado igual ou superior ao que adviria da atuação espontânea de condições favoráveis ao desenvolvimento." (JAGUARIBE, 1969, p.24). 
O processo de planejamento era tradicionalmente conduzido em duas etapas. A primeira envolvia a concepção dos planos, dividindo-se em diagnóstico contingencial e definição de objetivos e meios. Na fase seguinte, mecanismos legais e administrativos eram constituídos e entidades públicas e privadas mobilizadas para executálo. A avaliação de sua eficácia era exclusivamente econômica. Desse modo, como observa Lafer (1995), o objetivo prioritário dos planos era o crescimento da renda per capita.

No Brasil, o auge da intervenção estatal, via planejamento, começou na década de 1950, quando diversas políticas de fomento à industrialização foram empreendidas. Nos anos seguintes, a instauração do governo militar reforçou o caráter desenvolvimentista e centralizador do Estado. Ainda que diversos órgãos de planejamento setorial tenham sido criados, a contradição entre políticas explícitas e não-explícitas contribuiu para o desenvolvimento assimétrico das regiões brasileiras (MARTINE, 1994).

Na década de 1980, a crença dos gestores públicos nas virtudes do planejamento centralizado foi abalada pelo declínio dos índices nacionais de crescimento. Esse fato, associado à manutenção da onipotência estatal, favoreceu o clientelismo e, nos estados, inspirou estratégias de adaptação que pretendiam promover projetos regionais de interesse nacional e minimizar o impacto de programas federais inadequados ao contexto local (HADDAD, 1985). Os municípios, por sua vez, agiam como agenciadores de recursos do Estado (FARAH, 1999).

A partir da década de 1990, as crises fiscal e de governança do Estado motivaram profundas transformações em seu padrão de intervenção. O Estado empreendedor cedeu espaço ao Estado indutor do desenvolvimento e regulador de iniciativas públicas e privadas. Esse movimento, formalizado pela reforma do aparelho estatal (BRASIL, 1995; BRESSER-PEREIRA, 1997), teve como antecedentes a redemocratização (que restabeleceu o diálogo entre Estado e sociedade civil) e a descentralização administrativa (que transferiu atribuições e recursos aos municípios).

Segundo Paula e Motta (2003), no início da década de 1980 surgiram as primeiras experiências que romperam com o modo autoritário e centralizado de exercício do poder público. O debate sobre permeabilidade da burocracia estatal à participação popular estava em voga, atingindo seu ápice durante o movimento constituinte. Uma nova visão tornara-se hegemônica, clamando por um projeto político capaz de ampliar a participação social na formulação, implementação e controle das ações públicas.

Paralelamente, a Carta Constitucional de 1988 reconheceu os municípios brasileiros como membros da federação, condição associada exclusivamente aos estados. Esse fato ampliou significativamente a autonomia local por meio da transferência de responsabilidades e recursos. Assim, segundo Montoro (1999), as prefeituras são independentes para administrar serviços públicos, instituir tributos, elaborar a lei orgânica municipal, além de aplicar e prestar contas de sua receita. São competentes ainda pela oferta de concessões, pela criação de cargos públicos e pela concessão de auxílios e subvenções.

Embora o engajamento social e a autonomia local tenham avançado substancialmente, um longo caminho ainda deve ser percorrido para que seja instituída no Brasil uma democracia efetivamente participativa e descentralizada. Contudo, a análise de intervenções públicas contemporâneas tem revelado o protagonismo municipal, a consolidação de parcerias entre níveis de governo e o compartilhamento de responsabilidades entre o poder público e a sociedade civil organizada (FARAH, 1997; TENÓRIO; ROZEMBERG, 1997).

\section{Estatuto da cidade: instrumento e sintese do planejamento urbano no Brasil}

A cidade é produto da necessidade de coordenação, comunicação e troca entre indivíduos. Da pólis grega à metrópole moderna, essa complexa organização consolidou-se como o cenário onde as pessoas se relacionam, desenvolvem-se e experimentam as contradições da sociedade.

O século XX marca a urbanização do Brasil. Inverte-se, na década de 1970, a hegemonia do rural sobre o urbano. De acordo com Oliveira (2001), mais de $80 \%$ da população nacional reside na cidade, fato que sobrecarrega infra-estruturas e agrava a marginalização social e espacial. 
Diante de múltiplas demandas e interesses divergentes, o poder público atua como provedor de serviços e mediador de conflitos. No entanto, a insuficiência dos instrumentos de planificação e intervenção, aliada à omissão e à atuação seletiva, impediram a distribuição igualitária dos benefícios da urbanização.

Além de fornecer significativos recursos para uma gestão mais justa e eficiente do espaço urbano, o Estatuto da Cidade, aprovado em 2001, expressa a luta de diversos segmentos sociais que, durante décadas, trabalharam pela democratização da cidade. Com o objetivo de resumidamente recuperar esse movimento, os tópicos seguintes discutem os antecedentes dessa lei, assim como um de seus fundamentos: a gestão democrática da cidade.

\section{Antecedentes do estatuto da cidade}

Na década de 1960, a emergência do governo militar marcou o abandono do tratamento político-populista das demandas sociais. A busca por respostas técnicas tornou-se hegemônica, assim como a centralização decisória e a ênfase no planejamento. Nesse contexto, foram criados o Banco Nacional de Habitação (BNH) e o Serviço Federal de Habitação e Urbanismo (Serfhau). Como observa Grazia (2001), esses órgãos inspiraram-se na proposta de criação de uma entidade centralizadora de recursos e executora de políticas urbanas, concebida em 1963 no Seminário de Habitação e Reforma Urbana realizado em Petrópolis (RJ).

Segundo Bizelli (1998), o BNH e o Serfhau pretendiam legitimar o governo diante da população e recuperar a economia através da transferência de recursos para o setor da construção civil, gerando empregos e transformando o perfil das cidades. Em função de novas diretrizes, o Serfhau foi encarregado de definir e coordenar a política nacional de planejamento local integrado - processo que se tornou vital para que os municípios pudessem captar recursos junto ao governo central.

Nos anos 1970, as desigualdades e os problemas das cidades ganharam expressão política nos movimentos sociais urbanos. Tais mobilizações, juntamente com o conhecimento teórico sistematizado sobre o tema, estabeleceram as bases do Movimento pela Reforma Urbana. Seus princípios eram o direito à cidade e à cidadania, a gestão democrática das cidades e a função social da cidade e da propriedade.

De acordo com Grazia (2001), esses aspectos combatiam uma lógica de ocupação e gestão do espaço caracterizada pela mercantilização do solo, da habitação, dos serviços e equipamentos urbanos. O Estado, que não contrariou essa tônica, concebeu políticas e mecanismos reguladores discriminatórios. O Movimento pela Reforma Urbana notabilizou-se por enfatizar os seguintes pontos:

- as cidades são geradas pelo confronto e pela apropriação de agentes econômicos e sociais;

- as políticas e instrumentos jurídicos ou urbanísticos devem considerar a cidade real, reconhecendo a desigualdade e o conflito entre produtores e consumidores do espaço urbano;

- o Estado é obrigado a assegurar os direitos urbanos;

- é necessário o controle social do uso do solo, assim como a regulação pública da produção privada e do meio ambiente construído;

- o direito de propriedade deve submeter-se à função social da mesma;

- o direito à cidade e ao acesso igualitário aos bens e serviços urbanos é uma necessidade, devendo ser garantido por mecanismos redistributivos;

- o controle social e a participação da população organizada são condições básicas para a conquista de direitos, de políticas públicas que incorporem os excluídos e de novas referências para as cidades;

- a cidade deve ser reconhecida na sua totalidade e o planejamento deve ser repensado a partir da negociação entre os agentes que produzem e se apropriam do espaço urbano;

- é preciso assumir o esforço de construção de uma nova ética urbana contrária aos que pensam a cidade como mercado, visando à transformação da sociedade; 
- é necessário, como condição essencial para a construção e a implementação das estratégias propostas, o fortalecimento dos atores sociais e políticos (GRAZIA, 2001).

A primeira tentativa de constituir uma legislação específica para a gestão urbana data de 1983. Formulado sob a orientação do Conselho Nacional de Desenvolvimento Urbano (CNDU), o Projeto de Lei n⿳0 775 caracterizouse pela centralização excessiva e pela intenção de definir instrumentos e diretrizes para a política urbana, assim como sedimentar juridicamente o princípio da função social da propriedade (BASSUL, 2002). Apesar de despertar reações no Congresso Nacional e no segmento imobiliário, o debate sobre a Lei de Desenvolvimento Urbano prosperou somente a partir do debate constituinte.

Durante a elaboração da Constituição Federal de 1988, um movimento multissetorial trabalhou para incluir em seu texto elementos de direito urbanístico e de política urbana. Tais dispositivos, que retomavam os propósitos do Movimento pela Reforma Urbana, pretendiam garantir o direito à cidade, a democratização da gestão urbana e a defesa da função social da cidade e da propriedade. Para tanto, as políticas de desenvolvimento urbano deveriam ser regidas por planos diretores municipais (BASSUL, 2002; BRASIL, 2002).

Imediatamente após a promulgação da Carta Constitucional, foi organizado o Seminário Nacional pela Reforma Urbana de modo a avaliar as conquistas obtidas e a estabelecer diretrizes para a redação das constituições estaduais e das leis orgânicas municipais. Um ano depois, num segundo encontro, foi elaborada uma carta de princípios para orientar a redação dos planos diretores. Essas iniciativas consolidaram, em 1991, o III Fórum Nacional de Reforma Urbana (FNRU) que buscou divulgar seus propósitos durante a Conferência Rio Eco-92. Na véspera do evento, o IV FNRU politizou as questões urbanas, coordenando-as com problemas sociais e ambientais. Os fóruns posteriores constataram a falta de regulamentação das conquistas constitucionais e a desarticulação dos fóruns locais. A partir de 1998, a atuação do FNRU voltou-se para a aprovação do Estatuto da Cidade, cuja tramitação tinha sido retomada no Congresso Nacional (GRAZIA, 2001).

Mais de uma década havia passado e a implementação das diretrizes constitucionais para a cidade ainda dependia de uma legislação capaz de regulamentar instrumentos e orientar a elaboração de planos diretores. Nesse contexto, inicia-se na esfera federal um longo período de elaboração e negociações em torno de um projeto complementar ao capitulo de política urbana. O Projeto de Lei $\mathrm{n}^{\mathrm{o}}$ 5.788/90, conhecido como Estatuto da Cidade, foi aprovado em 2001 e vigora desde então (BRASIL, 2002).

\section{A gestão democrática da cidade}

O Estatuto da Cidade, a Lei n ${ }^{\circ} 10.257$ de julho de 2001, regulamentou os artigos 182 e 183 da Constituição Federal de 1988 que constam do capítulo sobre política urbana. O primeiro estabelece que a política de desenvolvimento urbano tem por objetivo ordenar o pleno desenvolvimento das funções sociais da cidade e garantir o bem-estar dos cidadãos. O instrumento básico dessa política é o plano diretor. O artigo 183 garante, mediante determinadas condições, a posse de áreas urbanas, possibilitando a regularização de espaços periféricos e a incorporação de moradias à cidade formal. Esses dispositivos - juntamente com os incisos XXII e XXIII do artigo $5^{\circ}$ da Carta Magna, que zelam pela função social da propriedade - representaram um significativo avanço no âmbito do direito coletivo urbano (OLIVEIRA, 2001).

Entretanto, no que se refere à possibilidade da cidade definir seus próprios rumos, estabelecendo prioridades e planejando seu desenvolvimento, o aspecto mais relevante do Estatuto da Cidade é a designação de mecanismos de democratização da gestão urbana. Historicamente, os problemas das cidades têm sido agravados pelo distanciamento entre planejamento, gestão e regulação urbanística e, também, pela precária interlocução do poder público com os diversos segmentos sociais - exceto no caso de grupos organizados cuja atividade profissional e econômica vincula-se diretamente à produção material da cidade (BRASIL, 2002).

Além de corrigir essas distorções, a democratização do processo decisório permite o envolvimento do cidadão no debate urbano, desvelando conflitos e favorecendo a construção de alternativas coerentes e negociadas. A participação social, desejável em todos os processos da política urbana, pode ser exercida na elaboração do plano diretor, em sua tramitação legislativa, na sua implementação e em suas revisões. Para tanto, o Estatuto da Cidade prevê a constituição de órgãos colegiados de política urbana, debates, audiências, consultas públicas, 
conferências, referendos e plebiscitos. Projetos de lei podem emergir da sociedade, que tem o poder de vetar medidas contrárias ao seu interesse. A aprovação de planos urbanísticos deve envolver, além da esfera legislativa, entidades representativas dos segmentos sociais interessados (OLIVEIRA, 2001).

Embora o Estatuto da Cidade tenha estabelecido os princípios da gestão urbana, ele delegou aos municípios a determinação democrática de seus fins e meios. Desse modo, o planejamento territorial (e suas interfaces com a planificação social e econômica local) aproximou-se substancialmente dos citadinos. Esse fato tornou possível e desejável a adoção de novos modelos de intervenção pública, com destaque para o planejamento estratégico municipal.

\section{Planejamento estratégico municipal}

No final da década de 1980, os EUA e a Europa começaram a incorporar elementos de estratégia em seus processos de planejamento urbano. Alguns aspectos contribuíram para esse fato. Inicialmente, em decorrência da dinâmica mundial das décadas imediatamente anteriores, a cidade deixa de ser percebida como um "[...] veículo de evolução geográfica natural e passa a demandar um processo amplo de criação, unindo as demandas locais aos condicionantes globais." (LOPES, 1998, p.68). Paralelamente, emerge a visão do município como ator social. Essa nova condição, segundo Castells e Borja (1996), se expressa tanto melhor quanto maior for sua capacidade de articular poder público, agentes econômicos, organizações sociais e cívicas, setores intelectuais, profissionais e meios de comunicação social. Finalmente, a competição por empreendimentos com capacidade de geração de empregos e tributos tem exigido das cidades, ações inovadoras, alternativas à guerra fiscal.

As premissas de planejamento urbano estratégico adotadas na América Latina são derivadas do modelo catalão, responsável pela revolução econômica e infra-estrutural de cidades como Barcelona e Bilbao, na Espanha. Sua origem, entretanto, está associada às práticas de planificação empresarial, mais precisamente à lógica Swot.

\section{Planejamento estratégico corporativo e municipal: semelhanças e diferenças}

A moderna concepção de estratégia organizacional originou-se do trabalho de Kenneth Andrews e Roland Christensen na Harvard Business School. No início da década de 1960, os autores buscaram pensar as organizações de modo holístico, integrando suas funções. No modelo que conceberam, a formulação de estratégias deveria envolver o confronto de pontos fortes e fracos internos com oportunidades e ameaças externas (MONTGOMERY; PORTER, 1998).

Dessa idéia emergiu a matriz Swot - strength (força), weakness (fraqueza), opportunity (oportunidade) e threat (ameaça) - que representa o cerne do planejamento estratégico corporativo e urbano. Em ambos os casos, a planificação busca alinhar esforços a propósitos comuns, capazes de maximizar a adaptação da empresa ou da cidade às tendências ambientais.

Diferentemente do plano diretor, o planejamento estratégico municipal não constitui uma norma legal. Ele representa um contrato político e social extensivo às partes que têm competência ou capacidade para desenvolvelo. Ainda assim, sua formalização gera um mecanismo de pressão para o cumprimento de seus objetivos (BORJA apud PFEIFFER, 2000). Como na esfera empresarial, a planificação estratégica urbana deve ser considerada um processo permanente. Contudo, os planos estratégicos corporativos e municipais apresentam diferenças que particularizam suas etapas de concepção e implementação. Essas divergências resultam, essencialmente, da natureza de seus sujeitos: os setores privado e público. Concebido por Pfeiffer (2000), o quadro 1 detalha esse aspecto. 
Quadro 1 - Diferenças entre os setores público e privado

\begin{tabular}{|c|c|c|}
\hline Atributo & Empresa privada & Setor público \\
\hline \multirow[t]{2}{*}{ Missão } & $\begin{array}{l}\text { limitada (a determinados produtos } \\
\text { e/ou serviços) }\end{array}$ & $\begin{array}{l}\text { ampla e não-específica (muitas vezes, } \\
\text { implicitamente subentendida e não } \\
\text { explicitamente definida) }\end{array}$ \\
\hline & $\begin{array}{l}\text { definida pela direção ou pelos } \\
\text { proprietários }\end{array}$ & obrigatória, na base de um mandato \\
\hline \multirow{3}{*}{ Visão } & $\begin{array}{l}\text { baseada na missão e na análise do } \\
\text { ambiente }\end{array}$ & determinada pela política \\
\hline & $\begin{array}{l}\text { coerente com as próprias } \\
\text { possibilidades }\end{array}$ & ampla e não-específica \\
\hline & & $\begin{array}{l}\text { muitas vezes, incoerente com os recursos } \\
\text { disponíveis }\end{array}$ \\
\hline \multirow{3}{*}{ Organização } & funcional & parcialmente funcional \\
\hline & linhas claras de decisão & superposição de funções e política \\
\hline & relativamente simples & complexa \\
\hline \multirow{3}{*}{ Clientela } & $\begin{array}{l}\text { limitada ao campo de operação da } \\
\text { empresa }\end{array}$ & ampla e diversificada \\
\hline & $\begin{array}{l}\text { relação definida através de compra } \\
\text { ou contrato }\end{array}$ & relações mal definidas \\
\hline & & "cliente" não é visto como tal \\
\hline \multirow{2}{*}{$\begin{array}{l}\text { Propósito da } \\
\text { atuação }\end{array}$} & obter lucro & servir ao público \\
\hline & cumprir uma missão & servir informalmente à política \\
\hline \multirow{2}{*}{ Forma de atuação } & tem de ser eficiente & não precisa ser eficiente \\
\hline & dinâmica & geralmente, lenta e burocrática \\
\hline
\end{tabular}

O reconhecimento da importância do planejamento estratégico pela cúpula da organização é um pressuposto básico para o seu desenvolvimento. Nas cidades, como a gestão é exercida por múltiplos atores, deve haver uma ampla reflexão sobre a necessidade, os custos e os benefícios do plano; caso contrário, sua legitimidade e sua sustentabilidade podem ser comprometidas.

A coordenação da participação dos stakeholders no município é mais complexa que na empresa. Para consultar e integrar ao plano diversos grupos de interesse, devem ser conduzidos processos de mediação, para melhorar a comunicação, facilitando a compreensão de questões técnicas e a tomada de decisão. Eles servem, ainda, para minimizar os efeitos negativos da disputa política.

Dessa forma, a organização do planejamento estratégico urbano deve ser cuidadosamente arquitetada. Se a prefeitura monopolizar sua condução, muitos setores podem distanciar-se por questões partidárias. Nesse contexto, emerge a possibilidade do compartilhamento de responsabilidades entre agentes públicos e privados, colocando em primeiro plano os temas críticos da cidade em detrimento de interesses particulares (PFEIFFER, 2000). 


\section{Elaboração e implementação de planos estratégicos municipais}

O modelo básico de planejamento estratégico, descrito por Mintzberg, Ahlstrand e Lampel (2000), envolve os estágios de fixação de objetivos, auditoria externa, auditoria interna, avaliação da estratégia, operacionalização da estratégia e programação do planejamento. Na primeira etapa, premissas como a missão e a visão da organização são estabelecidas. A segunda e a terceira consolidam a análise Swot. A quarta fase seleciona, entre vias possíveis, a mais coerente. A quinta busca decompor a estratégia em planos táticos, operacionais, orçamentos, cronogramas etc. Por fim, a sexta procura coordenar o universo de informações.

O desenvolvimento dos planos estratégicos municipais não foge muito dessa lógica. No entanto, suas etapas preliminar e final são significativamente diferentes. O Plano Estratégico de Juiz de Fora - seguindo o método prescrito em Esteve e Foxa (1999), Juiz de Fora (1999) e Lopes (1998) - apresentou as seguintes fases:

- organização da cooperação público-privada e da estrutura operacional permanente - envolveu a constituição de instrumentos legais e de negociação, além da consolidação do consórcio mantenedor, do comitê executivo, do conselho da cidade e do conselho diretor do plano (detalhados mais adiante no tópico "Estrutura organizacional do Plano Estratégico de Juiz de Fora");

- diagnóstico municipal - esse processo buscou levantar informações sobre a cidade e seu entorno, identificando e ouvindo atores-chave para consolidar as linhas temáticas de ação. Nesse ponto, foi empregada a matriz de relacionamento entre forças internas (pontos fortes e fracos) e externas (oportunidades e ameaças). Essa técnica ganha novos traços quando aplicada ao contexto urbano, conforme demonstra a figura 1;

Figura 1 - Matriz de análise estratégica

\begin{tabular}{|c|c|c|}
\hline & Oportunidades & Ameaças \\
\hline Pontos fortes & $\begin{array}{c}\text { Projetos de } \\
\text { expansão; } \\
\text { Concentrar } \\
\text { investimentos }\end{array}$ & $\begin{array}{l}\text { Projetos de } \\
\text { requalificação; } \\
\text { Incentivar } \\
\text { investimentos }\end{array}$ \\
\hline Pontos fracos & $\begin{array}{c}\text { Projetos de } \\
\text { investimento; } \\
\text { Investir em } \\
\text { desenvolvimento }\end{array}$ & $\begin{array}{c}\text { Estudos para } \\
\text { avaliação da } \\
\text { viabilidade de } \\
\text { investimentos }\end{array}$ \\
\hline
\end{tabular}

Fonte: Lopes (1998).

- estabelecimento do objetivo central e das linhas estratégicas - o objetivo central estabelece, sinteticamente, o modelo de cidade desejado. As linhas estratégicas representam os caminhos a percorrer entre a cidade acidental e a cidade intencional, desdobrando-se em objetivos específicos, ações e projetos;

- análise de propostas - começa com a captação de projetos que possam atender às demandas dos diversos segmentos locais. Tais iniciativas são priorizadas segundo critérios de viabilidade, sinergia (impacto sobre os fundamentos das linhas estratégicas), temporalidade (andamento do projeto e tempo demandado até sua conclusão) e imprescindibilidade. A alocação de projetos por linha estratégica e o agrupamento de iniciativas inter-relacionadas fornecem as informações para a formalização do plano;

- implementação do plano - a materialização do Plano Estratégico de Juiz de Fora corresponde ao desenvolvimento dos projetos selecionados. Trata-se, portanto, de um esforço coletivo e descentralizado. 


\section{Procedimentos metodológicos}

Esta pesquisa, de natureza qualitativa e exploratória, procurou investigar as práticas de gestão do Plano Estratégico de Juiz de Fora, detalhando suas características e sua estrutura. Os dados analisados foram obtidos por entrevistas pessoais, pela observação não-participante e através de análise documental.

\section{Levantamento de dados}

A entrevista é um processo de interação cujo propósito é o levantamento de informações. A elaboração de um roteiro de questionamentos determinou seu caráter semi-estruturado. Nesses casos, segundo Laville e Dionne (1999), as perguntas podem ser reorganizadas, suprimidas ou complementadas durante o diálogo. Foram consultados os três coordenadores do comitê executivo do PlanoJF, um dos quais concedeu duas entrevistas (uma para captação e outra para validação de dados). Coube aos pesquisadores, portanto, a seleção não-probabilística dos informantes.

O acompanhamento da rotina do comitê executivo teve como foco as atividades de apoio aos projetos, onde as práticas de gestão se manifestaram efetivamente. A conduta não-interveniente dos pesquisadores conferiu à observação a condição de não-participante. Embora não haja consenso sobre a fronteira entre as observações participante e não-participante, o debate conduzido por Haguette (1987) demonstra o alinhamento desta pesquisa com a segunda concepção.

O levantamento de dados contou, ainda, com a análise documental que, segundo Godoy (1995), inclui materiais escritos, estatísticas e elementos iconográficos. Assim, legislações, reportagens, publicações técnicas e relatórios de gestão associados ao PlanoJF foram consultados e as informações analisadas.

\section{Análise das informações}

Inicialmente, as informações foram organizadas por meio da transcrição e da leitura seletiva das entrevistas, que pretendia destacar as particularidades do Plano Estratégico de Juiz de Fora e as práticas de gestão de seu órgão executivo. Novas leituras foram realizadas para refinar a compreensão desses pontos. Num segundo momento, as notas da observação não-participante e o produto da análise documental foram integrados à síntese das entrevistas.

Como prevê Gomes (1995), foram estabelecidas articulações, orientadas para os objetivos da pesquisa, entre as referências teóricas e os resultados. Desse processo emergiram incertezas, evidências convergentes e novas práticas de gestão, que foram distribuídas em cinco categorias: "acompanhamento", "motivação", "coordenação", "sensibilização" e "financiamento". As quatro primeiras referem-se às ações prescritas para o comitê executivo e a última foi estabelecida pelos pesquisadores. Em uma segunda entrevista com um dos coordenadores do comitê executivo, as dúvidas remanescentes foram esclarecidas, o rol de práticas de gestão foi confirmado e suas descrições foram validadas.

\section{O Planejamento Estratégico de Juiz de Fora (PlanoJF)}

Em março de 2000 foi concluída a elaboração do Plano Estratégico de Juiz de Fora. Essa iniciativa caracterizou-se como uma ação intencional e organizada que empregou a participação cidadã e o consenso social para conceber um instrumento capaz de expressar os interesses prioritários do município (JUIZ DE FORA, 2000a).

O planejamento estratégico de cidades alinha-se com outros modelos de planejamento urbano que, segundo Vainer (2000), buscam preencher o vazio deixado pelo abandono do padrão tecnocrático, centralizado e autoritário que caracterizou a intervenção estatal em âmbito subnacional no Brasil. Seu desenvolvimento vem sendo fomentado na América Latina por diferentes agências, como o Banco Mundial e o Habitat. 


\section{Objetivo central, linhas estratégias e objetivos específicos do PlanoJF}

Uma vez definidas as forças e debilidades internas e tendências externas, a combinação dessas informações estabeleceu possíveis cenários que, contrapostos às conclusões do diagnóstico municipal, permitiram definir o seguinte objetivo central para o Plano Estratégico de Juiz de Fora:

Elevar Juiz de Fora a novos padrões de referência em serviços de educação, saúde, cultura, equilíbrio social e qualidade de vida, consolidando seu papel integrador do entorno. Desenvolver uma cidade com equilíbrio do espaço urbano, respeitosa da coisa pública e do meio ambiente, pólo econômico e logístico da Região Sudeste-Sul, orientada para os campos do conhecimento e da tecnologia. (JUIZ DE FORA, 2000a)

As linhas estratégicas do PlanoJF e seu desdobramento em objetivos específicos, detalhados no quadro 2, orientaram o trabalho dos grupos de propostas que destacaram 93 projetos (dos 334 apresentados) para implementação.

Quadro 2 - Linhas estratégicas e objetivos específicos do PlanoJF

\begin{tabular}{|c|c|}
\hline Linha Estratégica & Objetivos Específicos \\
\hline \multirow{2}{*}{$\begin{array}{l}\text { Juiz de Fora, cidade de } \\
\text { oportunidades }\end{array}$} & desenvolvimento de atividades produtivas \\
\hline & $\begin{array}{l}\text { oportunidades de desenvolvimento econômico e } \\
\text { profissional }\end{array}$ \\
\hline \multirow{2}{*}{$\begin{array}{l}\text { Juiz de Fora, cidade pólo da } \\
\text { Zona da Mata }\end{array}$} & infra-estrutura de desenvolvimento regional \\
\hline & serviços regionais de saúde e educação \\
\hline \multirow{4}{*}{$\begin{array}{l}\text { Juiz de Fora, cidade de } \\
\text { qualidade }\end{array}$} & qualidade urbana \\
\hline & meio ambiente \\
\hline & administração pública \\
\hline & serviços públicos \\
\hline
\end{tabular}

Fonte: Juiz de Fora (2000a).

\section{Estrutura organizacional do Plano Estratégico de Juiz de Fora}

O primeiro passo para o desenvolvimento do processo de planificação estratégica em Juiz de Fora ocorreu em março de 1997, durante a conferência “As cidades latino-americanas e do Caribe no novo século" realizada em Barcelona. Esse evento, organizado pelo Centro Ibero-Americano de Desenvolvimento Estratégico Urbano (Cideu), propôs-se a discutir, de várias perspectivas, o futuro das cidades ante a dinâmica global. Em abril do mesmo ano, as atividades do PlanoJF foram iniciadas através do seminário "A cidade como sujeito do desenvolvimento: a necessidade de uma visão de longo prazo", que envolveu cerca de 400 representantes da comunidade local. Nessa ocasião, foram apresentadas as experiências de Barcelona e do Rio de Janeiro (JUIZ DE FORA, 2000a).

A continuidade dos trabalhos ocorreu mediante a definição da estrutura organizacional fixa do plano, integrada pelos seguintes órgãos:

- conselho da cidade - órgão máximo de participação institucional e cidadã, composto por representantes dos mais diversos segmentos sociais responsáveis por homologar as diretrizes do plano; 
- conselho diretor - segmento responsável pelas decisões referentes à elaboração do plano, é composto por cidadãos com conhecimento e poder decisório sobre ações capazes de promover mudanças locais. É encarregado de orientar e acompanhar as decisões da equipe executiva;

- comitê executivo - órgão técnico, ligado à Diretoria de Planejamento e Gestão Estratégica da Prefeitura Municipal de Juiz de Fora, responsável pela implementação do plano e pela coordenação de trabalhos técnicos e administrativos concebidos pelas pessoas e grupos envolvidos; e

- consórcio mantenedor - entidade sem fins lucrativos, organizada para prover recursos financeiros e acompanhar o desenvolvimento do PlanoJF.

Além da configuração fixa, os processos de diagnóstico, concepção e execução do Plano Estratégico de Juiz de Fora demandaram a organização de estruturas variáveis empregadas entre (ou a partir de) períodos determinados. São estas:

- os grupos de diagnóstico - formados por equipes capazes de oferecer uma visão crítica da realidade e das tendências que afetam a cidade. Sua ação concentrou-se entre os meses de agosto e setembro de 1998;

- os grupos de propostas - compostos por agentes capazes de identificar projetos relevantes para a comunidade e de priorizá-los. Essa fase estendeu-se de abril a junho de 1999; e

- os grupos de impulsão - cuja atuação destina-se à promoção dos projetos e à provisão de recursos físicos, humanos e financeiros aos mesmos, por meio da combinação de esforços públicos e privados. O trabalho desses grupos foi iniciado em março de 2000 e estendeu-se até o fim de 2004.

A equipe do Plano Estratégico de Juiz de Fora contou, ainda, com os serviços de uma empresa de consultoria especializada para dar subsídios às ações do comitê executivo. A figura 2 detalha a estrutura organizacional do PlanoJF.

A atuação do poder público foi mais intensa durante as fases iniciais do PlanoJF. Assim, a consolidação de sua estrutura, as etapas de diagnóstico, a definição de objetivos e a seleção de projetos exigiram mais do governo local que a sua implementação. Nesse período destacaram-se as ações do comitê executivo e dos representantes da sociedade.

Os grupos de impulsão desempenharam, portanto, um papel fundamental na materialização do Plano Estratégico de Juiz de Fora. Por essa razão, suas especificidades serão detalhadas.

A principal função dos grupos de impulsão - prover recursos para o bom andamento dos projetos - é condicionada por três premissas. A primeira, descrita em Juiz de Fora (2000b), afirma que o plano não dispõe de orçamento próprio para a implementação dos programas selecionados. Outra, adverte que essa iniciativa não substitui os diversos agentes da cidade em sua capacidade de execução de projetos, mas os impele a agir.

O último princípio enuncia que o PlanoJF não cria uma estrutura específica de gestão dos projetos. No entanto, realiza o acompanhamento desse processo. 
Figura 2 - Estrutura organizacional do PlanoJF

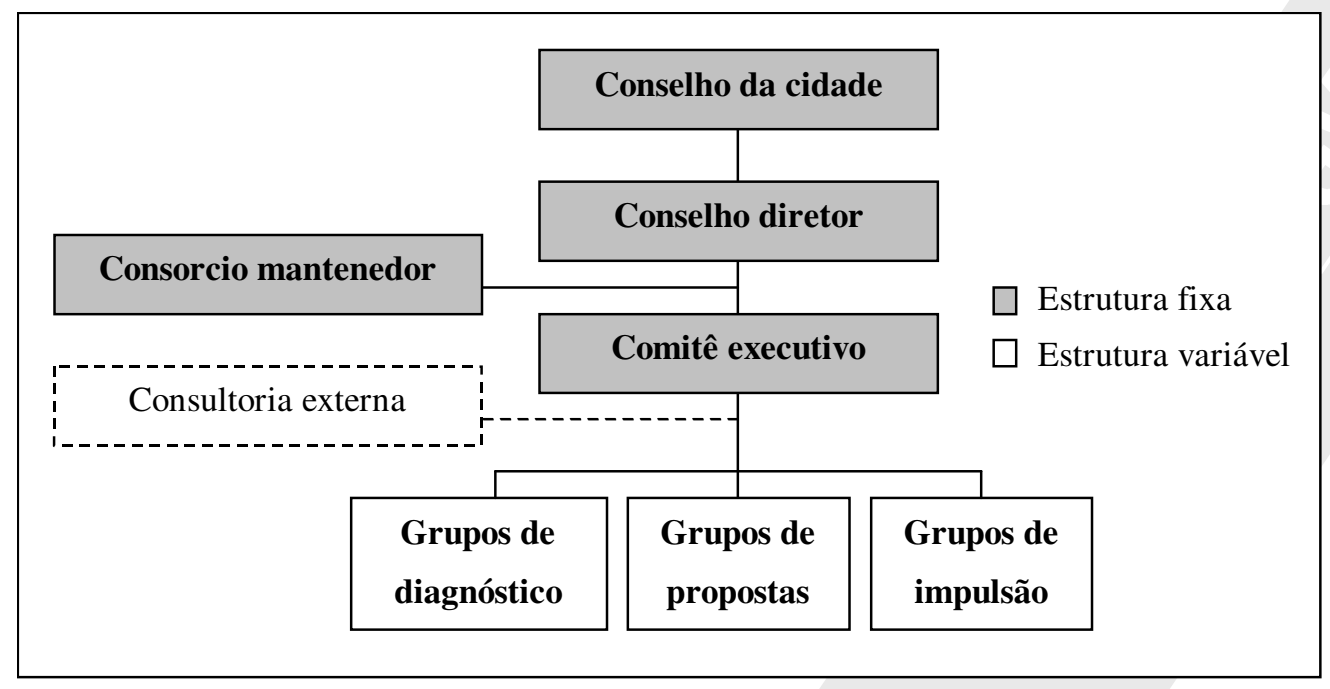

Fonte: Lopes (1998) e Juiz de Fora (2000a).

A ação do comitê executivo sobre as equipes de impulsão tende a variar conforme o andamento de cada iniciativa, sua natureza e os obstáculos que impedem suas ações. No que se refere especificamente ao primeiro caso, existem quatro situações possíveis, descritas no quadro 3.

\section{Quadro 3 - Andamento dos projetos: situações típicas}

\begin{tabular}{|c|c|}
\hline $\begin{array}{l}\text { 1. Há uma instituição ou entidade } \\
\text { responsável pela execução do } \\
\text { projeto que já atua nesse sentido }\end{array}$ & $\begin{array}{l}\text { 2. Os agentes que deveriam } \\
\text { assumir o projeto já estão } \\
\text { identificados. Porém, o processo } \\
\text { não foi iniciado }\end{array}$ \\
\hline $\begin{array}{l}\text { 3. Há uma pluralidade de agentes } \\
\text { que trabalham no } \\
\text { desenvolvimento do projeto }\end{array}$ & $\begin{array}{l}\text { 4. Não há nenhuma instituição ou } \\
\text { entidade envolvida com as } \\
\text { atividades do projeto }\end{array}$ \\
\hline
\end{tabular}

Fonte: Esteve e Foxa (1999).

Para cada situação, ações diferentes são desenvolvidas pelo comitê executivo do PlanoJF. A primeira demanda apenas a organização para o acompanhamento dos projetos. A seguinte implica motivar os agentes a assumirem a responsabilidade por tais iniciativas. A terceira exige a coordenação das partes, de modo a viabilizá-los. A última requer a sensibilização de possíveis atores capazes de se comprometerem com a execução dos programas. Nas fases onde um indivíduo ou entidade já está à frente do projeto, o comitê executivo age como facilitador, buscando recursos e dialogando com outros agentes (JUIZ DE FORA, 2000b).

\section{Práticas de gestão conduzidas pelo comitê executivo do PlanoJF}

A implementação do plano estratégico corresponde à materialização de seu conjunto de projetos. Dessa forma, sua coordenação visa garantir a eficácia e a sustentabilidade de cada programa. Para que sejam reconhecidos os aspectos gerenciais que dão sustentação a essa atividade, nos parágrafos seguintes, será discutido o conjunto de práticas conduzidas pelo comitê executivo do PlanoJF. Para tanto, esses itens foram alocados em cinco categorias. As quatro primeiras (acompanhamento, motivação, coordenação e sensibilização) estão associadas às 
ações prescritas para esse órgão, conforme o andamento de cada projeto (JUIZ DE FORA, 2000b). A última (financiamento) foi estabelecida pelos pesquisadores para contemplar algumas ações destinadas a esse fim.

A etapa de acompanhamento tem dois propósitos. O primeiro, garantir a manutenção das atividades dos projetos. O segundo, ao qual se associa o sétimo item, é efetivar o controle dos mesmos. As práticas vinculadas a essa fase são as seguintes:

- neutralização da questão político-partidária - para garantir um ambiente de deliberação plural e isento, tanto quanto possível, da dinâmica política local;

- seleção e disseminação de informação estratégica - o comitê executivo do PlanoJF investe uma parcela significativa de seu trabalho nessa atividade, cujo objetivo é manter os grupos de impulsão atualizados sobre qualquer dado que contribua para a viabilidade dos projetos;

- minimização dos efeitos da assimetria de investimentos - em cada projeto, os agentes empenham recursos de natureza e magnitude diferentes. Esse fato pode despertar, em estratos da equipe, sentimentos contraditórios, tais como impotência ou posse, capazes de inibir a participação;

- constituição de grupos de persuasão - a continuidade das ações da equipe de impulsão, por vezes, depende de decisões ou recursos que extrapolam seus limites. Nesses casos, as instâncias encarregadas de suprir tais demandas podem ser impelidas a agir por um ou mais indivíduos engajados no projeto;

- estímulo a compromissos mútuos - nas reuniões de impulsão, é fomentado tanto o comprometimento interpessoal quanto o compromisso entre os agentes e o projeto. Essa prática tende a contribuir para a coesão do grupo e a efetividade de suas ações;

- integração de agentes-chave - prática que consiste em agregar às equipes de trabalho pessoas que possam agir como facilitadoras em eventos futuros;

- estabelecimento de indicadores qualitativos e quantitativos - cada projeto em execução é acompanhado por um conjunto de indicadores definidos a partir de suas especificidades. A cada semestre, o comitê executivo expede um relatório que é enviado ao conselho diretor do PlanoJF, indicando os avanços obtidos;

Foram reconhecidas quatro estratégias empregadas para motivar atores previamente identificados a se responsabilizarem pelos projetos:

- convocações exaustivas - todos os agentes selecionados para integrar o grupo de impulsão, ainda que não participem, são informados sobre a data e a pauta das reuniões. Essa prática mantém a equipe sempre acessível a novos colaboradores;

- seleção e disseminação de informação estratégica - dados sobre os resultados das atividades de impulsão, sobre novas possibilidades de ação e possíveis recursos a captar são comunicados para motivar os grupos de trabalho;

- busca por credibilidade social - o engajamento de agentes representativos (tais como instituições, empresas tradicionais ou pessoas públicas) é estimulado para conferir credibilidade aos grupos de trabalho, favorecendo a adesão de novos atores;

- emprego do poder de compra do poder público local - a Prefeitura Municipal de Juiz de Fora, em parceria com órgãos setoriais, estabeleceu como critério de aptidão em processos licitatórios, a participação de alguns de seus fornecedores em projetos de qualificação institucional promovidos pelo PlanoJF.

A pesquisa identificou quatro das práticas destinadas a coordenar a ação de agentes dispersos:

- execução de aspectos consensuais - são priorizados pontos sobre os quais o grupo demonstra irrestrita concordância. Pontos controversos não são abordados de imediato para não retardar atividades e não gerar desgastes prematuros; 
- dinamização das ações através de subgrupos de trabalho - em muitos grupos foram constituídas equipes de trabalho que atuavam paralelamente à conclusão de atividades distintas;

- é mantido o foco nas idéias e não nas pessoas - essa prática tende a tornar as críticas impessoais, evitando embates improdutivos;

- dissolução de posicionamentos intransigentes - a defesa radical de opiniões é desestimulada, pois impede o consenso e inibe a reavaliação de condutas.

Dentre as práticas que têm por objetivo sensibilizar indivíduos ou organizações a aderirem aos projetos, destacam-se:

- as palestras estratégicas e as visitas técnicas - duas atividades cujo objetivo é instruir e motivar os agentes pelo contato com outras experiências onde atividades semelhantes foram desenvolvidas;

- comunicação institucional - desde as primeiras atividades do PlanoJF, seus esforços de comunicação procuraram estimular a participação. Essa atividade foi particularmente intensa no período de captação de projetos;

- concorrência entre atores - essa prática consiste em convidar indivíduos ou entidades que, devido à similaridade de suas atividades profissionais, apresentam, em relação aos projetos, interesses e possibilidades de ação semelhantes entre si;

- contrapartida relacionada com a participação social - o convite à participação busca integrar uma pluralidade de indivíduos, ainda que supostamente antagônicos, como, por exemplo, sindicatos patronais e de classe.

Para concluir a exposição das práticas de gestão conduzidas pelo comitê executivo do Plano Estratégico de Juiz de Fora serão apresentadas duas estratégias de financiamento que contribuíram para a execução de alguns projetos:

- a compensação ambiental - passivos ambientais associados a uma empresa da região foram convertidos em recursos para um projeto alinhado com a causa ambiental;

- habilitação às linhas de crédito via projetos participativos - a participação popular é um dos critérios mais relevantes definidos por agências de fomento para a concessão de recursos. Essa característica, presente em diversos projetos em impulsão, tornou-os aptos a captar recursos no Brasil e no exterior.

As práticas de gestão identificadas buscam, essencialmente, promover a participação e a motivação dos integrantes dos projetos. Podemos observar ainda que a provisão de recursos físicos, humanos e financeiros foi uma preocupação constante do comitê executivo. O estabelecimento de um ambiente de deliberação e negociação permitiu que o PlanoJF fosse calcado num efetivo dialogismo. Isso contribuiu para a adequação de suas propostas e para a sua sustentabilidade, conseguida com recursos não-estatais, com participação social e um compartilhamento de responsabilidades em que os cidadãos foram, ao mesmo tempo, co-autores e beneficiários das ações empreendidas.

\section{Considerações finais}

Nas duas últimas décadas, novas demandas e recursos foram apresentados às cidades brasileiras. As novas demandas emergem da atual condição federativa dos municípios e do processo de descentralização estatal. Os recursos têm múltiplas origens. Em termos gerenciais, a capacidade empreendedora das prefeituras depende menos do "bom relacionamento" com o poder central e mais do tecido social local, potencializado por sua capacidade de induzir e coordenar esforços. Na esfera normativa, novos instrumentos, como o Estatuto da Cidade e o planejamento estratégico urbano, confiam ao município a gestão de seu território e de seu desenvolvimento.

O propósito do Estatuto da Cidade é viabilizar os artigos constitucionais que definem os objetivos da política de desenvolvimento urbano e a função social da cidade e da propriedade. Além disso, ele estabelece formas de 
democratização da gestão municipal como os projetos de iniciativa popular, os órgãos colegiados de política urbana e as consultas públicas.

Ao contrário do Estatuto da Cidade, o planejamento estratégico urbano não é uma referência legal. Ele representa um contrato político para decisão partilhada dos rumos da cidade com foco no longo prazo. Nota-se, portanto, que a descontinuidade política pode comprometer sua efetividade.

O Plano Estratégico de Juiz de Fora, além de vigorar por mais de um mandato, pôde contribuir para a reeleição do prefeito que o promoveu, dando consistência ao discurso que defendia a continuidade de uma gestão moderna e participativa. Apesar disso, um novo processo de planejamento estratégico não foi iniciado. Curiosamente, nas eleições de 2004, a disputa entre o candidato da situação e o diretor municipal de planejamento - ambos citando o PlanoJF como um feito importante - favoreceu a vitória de um terceiro concorrente.

Embora a pesquisa não possa afirmar a parcela do PlanoJF que saiu do papel, sua interrupção não foi absoluta. Ao contrário, muitos projetos com fins determinados foram efetivados (beneficiando permanentemente a cidade) e outros tiveram sua continuidade garantida pelo encaminhamento de projetos de lei à Câmara de Vereadores. Sem contar que há, ainda, projetos sustentados pela força de seus propósitos e pela motivação de seus integrantes.

O PlanoJF representou para a cidade um momento de reflexão, onde atores heterogêneos discutiram problemas comuns. O estudo detalhado de dois de seus projetos (OLIVEIRA; OLIVEIRA; SIQUEIRA, 2004) evidenciou o aprendizado, as contradições, os conflitos e as soluções surgidas nesse período. Se extrapolados para todas as propostas, esses aspectos dão uma dimensão da dinâmica social do plano.

Através do PlanoJF, a prefeitura ampliou sua capacidade de ação, apresentando uma alternativa à tradicional resposta "não há recursos". Ainda que o estímulo à participação social possa ser visto, nesse contexto, como estratégia de transferência de responsabilidades, a atuação solitária do poder local teria levado a uma menor número de realizações e, certamente, resultado em mais equívocos.

Do ponto de vista dos citadinos, o engajamento nas atividades do plano contribuiu para romper a tipificação social que afastava os representantes "da prefeitura", "das ONGs" e "do mercado". As particularidades de cada campo - que condicionam a visão de mundo e a autonomia decisória de seus membros - tornaram-se evidentes nos momentos de deliberação, assim como a necessidade da mútua compreensão de interesses, possibilidades e limitações como pré-requisito para o diálogo. 


\section{Referências}

BASSUL, J. R. Reforma urbana e Estatuto da Cidade. Eure, Santiago, v.28, n.84, p.133-144, set. 2002.

BIZELLI, J. L. As cidades brasileiras frente ao século XXI: desafios e perspectivas. In: INTERNATIONAL CONGRESS OF THE LATIN AMERICAN STUDIES ASSOCIATION, 18., 1998, Chicago. Disponivel em: <http://lasa.international.pitt.edu/Lasa98-tracks/98cities.htm> Acesso em: 11 mar. 2006.

BRASIL. Câmara dos Deputados. Estatuto da Cidade: guia para implementação pelos municípios e cidadãos. Brasilia, DF, 2002. (Série Fontes de referência. Legislação, n.46).

BRASIL. Ministério da Administração Federal e Reforma do Estado. Plano Diretor da Reforma do Aparelho do Estado. Brasília, DF, 1995.

BRESSER-PEREIRA, L. C. A Reforma do Estado dos anos 90: lógica e mecanismos de controle. Cadernos Mare da Reforma do Estado, Ministério da Administração Federal e Reforma do Estado, Brasília, DF, 1997.

CASTELLS, M.; BORJA, J. As cidades como atores políticos. Novos Estudos Cebrap, São Paulo, n.45, p.152-166, jul. 1996.

ESTEVE, J. M. P.; FOXA, M. F. La estratégia de las ciudades. Los planes estratégicos como instrumento. Barcelona: Disputació de Barcelona, 1999.

FARAH, M. F. S. Gestão publica e cidadania: iniciativas inovadoras na administração subnacional no Brasil. Revista de Administração Pública, Rio de Janeiro, v.31, n.4, p.126-156, jul./ago. 1997.

. Parcerias, novos arranjos institucionais e políticas locais. In: FUNDAÇÃO PREFEITO FARIA LIMA. O municipio no século XXI, cenários e perspectivas. São Paulo: Cepam, 1999. p.325-343.

GODOY, A. S. Pesquisa qualitativa: tipos fundamentais. Revista de Administração de Empresas, São Paulo, v.35, n.3, p.20-29, maio/jun. 1995.

GOMES, R. Análise de dados em pesquisa qualitativa. In: MINAYO, M. C. S. (Org.). Pesquisa social: teoria, método e criatividade. Petrópolis: Vozes, 1995. cap.4, p.67-80.

GRAZIA, G. Reforma urbana e o Estatuto da Cidade. In: Gestão urbana e de cidades. Belo Horizonte: Fundação João Pinheiro/Lincoln Institute of Land Policy, 2001.

HADDAD, P. R. Dimensões do planejamento estadual no Brasil: análise de experiências. Rio de Janeiro: Ipea, 1985.

HAGUETTE, T. M. F. Metodologias qualitativas na sociologia. Petrópolis: Vozes, 1987.

JAGUARIBE, H. Desenvolvimento econômico e desenvolvimento político. Rio de Janeiro: Paz e Terra, 1969.

JUIZ DE FORA. Prefeitura Municipal. Diagnóstico PlanoJF. Juiz de Fora, 1999.

JUIZ DE FORA. Prefeitura Municipal. Plano Estratégico de Juiz de Fora. Juiz de Fora, 2000a.

JUIZ DE FORA. Prefeitura Municipal. Grupos de impulsão: considerações metodológicas. Juiz de Fora, $2000 \mathrm{~b}$.

LAFER, B. M. Planejamento no Brasil. São Paulo: Perspectiva, 1995.

LAVILLE, C.; DIONNE, J. A construção do saber: manual de metodologia da pesquisa em ciências humanas. Belo Horizonte: UFMG, 1999.

LOPES, R. A cidade intencional: o planejamento estratégico de cidades. Rio de Janeiro: Mauad, 1998.

MARTINE, G. Estado, economia e mobilidade geográfica: retrospectiva e perspectiva para o fim do século. Revista Brasileira de Estudo de População, Campinas, v.11, n.1, p.41-59, jan./jul. 1994.

MIGLIOLI, J. Introdução ao planejamento econômico. São Paulo: Brasiliense, 1982.

MINTZBERG, H.; AHLSTRAND, B.; LAMPEL, J. Safári de estratégia: um roteiro pela selva do planejamento estratégico. Porto Alegre: Bookman, 2000.

MONTGOMERY, C. A.; PORTER, M. E. Estratégia: a busca da vantagem competitiva. Rio de Janeiro: Campus, 1998.

MONTORO, A. F. Descentralização e participação: importância do município na democracia. In: FUNDAÇÃO PREFEITO FARIA LIMA. 0 município no século XXI, cenários e perspectivas. São Paulo: Cepam, 1999. p.297-304.

OLIVEIRA, I. C. E. Estatuto da Cidade, para compreender... Rio de Janeiro: Ibam/Duma, 2001. 
OLIVEIRA, V. C. S.; OLIVEIRA, L. C. F. S.; SIQUEIRA, E. D. Combinação de esforços públicos e privados em âmbito municipal: a construção de ordens sociais negociadas. In: ENCONTRO DE ADMINISTRAÇÃO PÚBLICA E GOVERNANÇA, 2004, Rio de Janeiro. Anais... Rio de Janeiro, 2004.

PAULA, A. P. P.; PRESTES MOTTA, F. C. Administração pública popular: participação cidadã e melhorias sustentáveis na qualidade de vida no Brasil. In: ENCONTRO NACIONAL DOS PROGRAMAS DE PÓS-GRADUAÇÃO EM ADMINISTRAÇÃO, 27., 2003, Atibaia. Anais... Atibaia, 2003.

PFEIFFER, P. Planejamento estratégico municipal no Brasil: uma nova abordagem. Brasilia, DF: Enap, 2000. (Texto para discussão, n.37).

TENÓRIO, F. G.; ROZENBERG, J. E. Gestão publica e cidadania: metodologias participativas em ação. Revista de Administração Pública, Rio de Janeiro, v.31, n.4, jul./ago. 1997.

VAINER, C. Pátria, empresa e mercadoria: notas sobre a estratégia discursiva do planejamento estratégico urbano. In: ARANTES, 0.; VAINER, C.; MARICATO, E. A cidade do pensamento único: desmanchando consensos. Petrópolis: Vozes, 2000. 